\title{
Psychological intervention in acute dental pain: review
}

\author{
W. Jerjes, ${ }_{1}^{1}$ C. Hopper, ${ }_{1}^{2}$ M. Kumar, ${ }^{3}$ T. Upile, ${ }^{4}$ G. Madland ${ }_{1}^{5}$ S. Newman ${ }^{6}$ and C. Feinmann ${ }^{7}$
}

Acute dental pain is an unpleasant experience. This article studies acute dental pain and examines the role of psychological intervention. After identification of the psychological factors associated with dental pain we go on to assess the role of psychological interventions.

Acute dental pain is traditionally classified into three groups: toothache, perioperative pain and postoperative pain. The majority of studies conclude that psychological measures of pain are affected by anxiety.

Various psychological intervention techniques have been employed to try to relieve anxiety including distraction strategies, relaxation techniques,

\footnotetext{
${ }^{1}$ Honorary Lecturer in Oral \& Maxillofacial Surgery, Eastman Dental Institute \& University College London; ${ }^{2}$ Head of Academic Surgical Unit, Consultant Oral \& Maxillofacial Surgeon, Senior Lecturer, Department of Oral and Maxillofacial Surgery, Eastman Dental Institute \& University College London; ${ }^{3}$ Specialist Registrar in Oral and Maxillofacial Surgery, University College London Hospitals: ${ }^{4}$ Specialist Registrar, Department of Head \& Neck Surgery, University College London Hospitals; ${ }^{5}$ Clinical Tutor in Oral Medicine, Eastman Dental Institute \& Hospital and Research Fellow in Health Psychology, Royal Free \& University College Medical School; ${ }^{6}$ Professor, Unit of Health Psychology, Centre for Behavioural and Social Sciences in Medicine, University College London; ${ }^{7}$ Reader in Psychiatry, Eastman Dental Institute \& Hospital, and Royal Free \& University College Medical School

${ }^{*}$ Correspondence to: Charlotte Feinmann, MSc, MD, Department of Oral and Maxillofacial Surgery,

Eastman Dental Institute for Oral Healthcare Sciences, 256 Gray's Inn Road, London WC1X 8LD

Email:rejucfe@ucl.ac.uk
}

\section{Refereed Paper}

Accepted 9 June 2006

DOI: $10.1038 /$ bdj.2007.227

${ }^{\circledR}$ British Dental Journal 2007; 202: 337-343 hypnosis, sensory information, perceived control, positive dental experience, systemic desensitisation, psychotherapy, support groups and dental phobia clinics. The success of these interventions is reviewed.

\section{INTRODUCTION}

Pain is an unpleasant sensation ranging from mild discomfort to agonising distress; it is usually associated with real or potential tissue damage. Acute dental pain may involve toothache, dental sensitivity, perioperative pain or postoperative pain. Fear of pain may lead patients to avoid dental treatment; acute dental pain is a clinical problem.

Anxiety has been identified as being one of the major factors that impact on dental pain. ${ }^{1,2}$ However, expected pain is less intense than unexpected pain. ${ }^{3}$ Eighty-four percent of adults attending a dental clinic reported sudden discomfort. ${ }^{4}$ In acute pain situations anxiety may lead to the perception that normally non-painful stimuli are painful; individuals differ in their pain perception and reaction according to culture, social environment, gender and individual cognitive and emotional factors; several questionnaires have been developed to measure pain and anxiety (Table 1).

Maggirias and Locker $^{5}$ found that patients with high scores on the Pain Tolerance Scale (PTS) were less likely to report painful dental experiences; those patients have previously agreed with the statement 'I would be angry if I felt pain during dental treatment' and disagreed with the statement 'If I am in pain I just put up with it', suggesting that patients may either interpret sensations and experiences as something other than pain or those patients are more successful at conveying concerns regarding pain to dentists. Dentists may then modify their clinical and interpersonal approach to minimise the possibility of pain or the perception of pain. Reports of pain were associated with the type of treatment received and a number of baseline sociodemographic and psychological factors.

Toothache does not affect perception of pain in any other part of the body. A study by Sigurdsson and Maixner ${ }^{6}$ involved 17 subjects of whom 10 presented with painful toothache and the rest were healthy volunteers. They concluded that measures of thermal pain perception and forearm ischemic pain perception were not altered by the 


\begin{tabular}{|c|c|}
\hline BHS & Beck Hopelessness Scale \\
\hline CISS & $\begin{array}{l}\text { Coping Inventory for Stressful } \\
\text { Situations }\end{array}$ \\
\hline DAS & Dental Anxiety Scale \\
\hline DBS & Dental Belief Survey \\
\hline DDS & Descriptor Differential Scale \\
\hline DFS & Dental Fear Scale \\
\hline EPQ & Eysenck Personality Questionnaire \\
\hline $\mathrm{GHO}$ & General Health Questionnaire \\
\hline IBES & $\begin{array}{l}\text { Illness Behaviour Encouragement } \\
\text { Scale }\end{array}$ \\
\hline IBO & Illness Behaviour Questionnaire \\
\hline $\mathrm{IDCl}$ & lowa Dental Control Index \\
\hline PANAS & $\begin{array}{l}\text { Positive and Negative Affect } \\
\text { Scales }\end{array}$ \\
\hline PAS & Pain Anxiety Scale \\
\hline $\mathrm{PCl}$ & Patient Comfort Index \\
\hline PCS & Pain Catastrophising Scale \\
\hline POMS & Profile of Mood States \\
\hline PTS & Pain Tolerance Scale \\
\hline RLOC & Recovery Locus of Control \\
\hline SHSS & $\begin{array}{l}\text { Stanford Hypnotic Susceptibility } \\
\text { Scale }\end{array}$ \\
\hline STAI & State Trait Anxiety Inventory \\
\hline TAO & Tellegen Absorption Questionnaire \\
\hline TAS & Toronto Alexithymia Scale \\
\hline VAS & Visual Analogue Scale \\
\hline
\end{tabular}

occurrence of toothache. In contrast, sustained noxious forearm ischemia produced a marked reduction in the intensity, unpleasantness and spatial distribution of pulpal pain.
Forty-six dental patients experiencing pain due to acute irreversible pulpitis and 33 healthy controls were involved in a study ${ }^{7}$ to determine whether the presence of pain could be influenced by gender. These data suggest that the gender difference in thermal pain sensitivity frequently reported in pain-free subjects appears to be absent in patients presenting with acute dental pain.

Karadottir et al.'s ${ }^{8}$ assessment of pain experienced by 26 patients during periodontal maintenance treatment (probing and instrumentation) using the Visual Analogue Scale (VAS) and anxiety questionnaires, showed that patients showed low pain responses to both probing and instrumentation. However, by using an arbitrary threshold of pain frequency, approximately $15 \%$ of the patients had a painful experience. They concluded that recognition of patients who are likely to experience pain during periodontal treatment could be facilitated by the use of two questions on dental anxiety and the VAS response to probing during examination.

Postoperative pain can be associated with all dentoalveolar surgical procedures, which is considered to be a normal physiological response to surgical treatment.

Pain is common; the role of psychological factors associated with reports of dental pain (toothache, perioperative and postoperative pain) and psychological interventions employed to reduce dental pain will be reviewed.

\section{DISCUSSION}

\section{Dental pain without psychological}

manipulation

Weisenberg et al. ${ }^{9}$ studied the reaction of 75 black, white and Puerto Rican patients in an outpatient dental emergency clinic (Table 2). Pain measures showed no difference, while psychological measures showed that Puerto Ricans scored the highest level in State Trait Anxiety Inventory (STAI), Dental Anxiety Scale (DAS) and attitude differences. AntczakBouckoms and Bouckoms ${ }^{10}$ studied 61 patients attending a dental hospital (DH) and found no significant difference on any scale of the Illness Behaviour Questionnaire (IBQ) between 'acute pain' and 'no pain' groups, while significant difference in the 'chronic pain' group was noted.

Kunzelmann and Dunninger ${ }^{11}$ developed a questionnaire including DAS and the Dental Beliefs Survey (DBS) as subscales to examine the epidemiology of dental fear and dental beliefs in Germany; pain measures were selfreported. Four hundred and seventy-four patients were surveyed before treatment. It was concluded that patients attending in pain are more anxious and have more negative beliefs about the dentist than those not in pain.

Of the three studies ${ }^{9-11}$ of patients with toothache, Weisenberg et al. ${ }^{9}$ and Antczak-Bouckoms and Bouckoms ${ }^{10}$ used fairly crude measures of pain. Kunzelmann and Dunniger ${ }^{11}$ found patients attending in pain were more anxious and had more negative beliefs than those not in pain, which is unsurprising since it is those who are anxious who are more likely to put off a visit to the dentist until they are in pain.

Nine adult females attending DH were surveyed by Hargreaves et al. ${ }^{12}$ using VAS to measure pain and anxiety pre and perioperatively (Table 3); plasma B-endorphin was also measured. They found that individual perioperative pain, but not anxiety, correlated inversely with the pre- to perioperative rise in plasma endorphin-like immunoreactivity.

Table 2 Studies detailing patients' reactions in dental clinics

\begin{tabular}{l|l|l|l|l}
\hline Study & Subject groups & $\begin{array}{l}\text { Number } \\
\text { Drop-out }\end{array}$ & Pain measures & $\begin{array}{l}\text { Psychological } \\
\text { measures }\end{array}$ \\
\hline $\begin{array}{l}\text { Weisenberg et al. } \\
\text { attendees in pain; } \\
\text { ethnic differences }\end{array}$ & $\begin{array}{l}75 \\
1 \%\end{array}$ & $\begin{array}{l}\text { Direct questions of cur- } \\
\text { rent and expected pain }\end{array}$ & $\begin{array}{l}\text { STAI, DAS interview } \\
\text { and dentist ratings }\end{array}$ & $\begin{array}{l}\text { No reported differences in current or } \\
\text { expected pain between ethnic groups }\end{array}$ \\
\hline $\begin{array}{l}\text { Antczak-Bouckoms } \\
\text { and Bouckoms }\end{array}$ & $\begin{array}{l}\text { Consecutive patients } \\
\text { attending DH }\end{array}$ & $\begin{array}{l}61 \\
10 \%\end{array}$ & $\begin{array}{l}\text { Simple report of pain } \\
\text { and duration }\end{array}$ & IBO \\
\hline $\begin{array}{l}\text { Kunzelmann and } \\
\text { Dunninger }\end{array}$ & $\begin{array}{l}\text { Random sample of } \\
\text { GDP and DH adult } \\
\text { patients }\end{array}$ & $\begin{array}{l}474 \\
0 \%\end{array}$ & $\begin{array}{l}\text { Self-report } \\
\text { between 'acute pain' and 'no pain' groups; } \\
\text { chronic group 'differed' }\end{array}$ & $\begin{array}{l}\text { Patients attending in pain more anxious } \\
\text { ( } p<0.001), \text { and having more negative } \\
\text { beliefs about the dentist ( } p<0.001), \text { than } \\
\text { those not in pain }\end{array}$
\end{tabular}


Table 3 Studies detailing patients' reactions in dental clinics

\begin{tabular}{|c|c|c|c|c|c|}
\hline Study & Subject groups & $\begin{array}{l}\text { Number } \\
\text { Drop-out }\end{array}$ & Pain measures & $\begin{array}{l}\text { Psychological } \\
\text { measures }\end{array}$ & Findings \\
\hline Hargreaves et al. & $\begin{array}{l}\text { Adult patients attending } \\
\text { DH for wisdom teeth } \\
\text { removal }\end{array}$ & $\begin{array}{l}9 \\
0 \%\end{array}$ & $\begin{array}{l}\text { VAS (pre- and } \\
\text { perioperatively) }\end{array}$ & $\begin{array}{l}\text { VAS (pre- and } \\
\text { perioperatively) }\end{array}$ & $\begin{array}{l}\text { Individual perioperative correlated inversely with } \\
\text { pre- to perioperative rise in plasma endorphin-like } \\
\text { immunoreactivity }(p<0.05)\end{array}$ \\
\hline Kent and Warren & $\begin{array}{l}\text { Adult patients attending } \\
\text { general dental practice }\end{array}$ & $\begin{array}{l}125 \\
25 \%\end{array}$ & $\begin{array}{l}\text { VAS (pre- and } \\
\text { postoperative) }\end{array}$ & $\begin{array}{l}\text { DAS (pre- and } \\
\text { postoperative) }\end{array}$ & $\begin{array}{l}\text { Patients reporting a high discrepancy between expected } \\
\text { and experienced pain, but not anxiety, less confident } \\
\text { about the typicality of the appointment }(p<0.005)\end{array}$ \\
\hline Chaves and Brown & $\begin{array}{l}\text { Adult patients attending } \\
\text { DH and GDP }\end{array}$ & $\begin{array}{l}75 \\
10 \%\end{array}$ & Likert-type scale & $\begin{array}{l}\text { STAI, DAS, TAS, } \\
\text { RLOC, Likert-like } \\
\text { stress scale }\end{array}$ & $\begin{array}{l}\text { No difference in pain ratings between patients using } \\
\text { coping strategies and those who denied cognitive } \\
\text { activity, nor between deniers and catastrophisers }\end{array}$ \\
\hline Arntz et al. & $\begin{array}{l}\text { Volunteer adult patients } \\
\text { in GDP }\end{array}$ & $\begin{array}{l}40 \\
23 \%\end{array}$ & VAS & DAS, VAS & $\begin{array}{l}\text { Anxious dental patients tend to expect more pain than } \\
\text { fearless patients and require several disconfirmations } \\
\text { to become more accurate in their predictions; dental } \\
\text { anxiety not associated with pain experienced }\end{array}$ \\
\hline
\end{tabular}

One hundred and twenty-five patients reported a high discrepancy between expected and experienced pain, but not anxiety, when they were asked to complete a VAS and a DAS ${ }^{13}$ results showed that patients reporting a high discrepancy between expected and experienced pain, but not anxiety, were less confident about the typicality of the appointment.

Chaves and Brown ${ }^{14}$ employed spontaneous cognitive strategies during a structured interview on 75 patients undergoing dental extractions or mandibular block injections. They found no differences in pain ratings between patients using coping strategies and those who denied cognitive activity, or between deniers and catastrophisers. In another study, the relationships between expectations and experiences of pain and anxiety were investigated in
40 dental pain patients using VAS and DAS. ${ }^{15}$ It was suggested that anxious patients tend to expect more pain than fearless patients and require several disconfirmations to become more accurate in their predictions; dental anxiety was not associated with pain experienced.

Of the four studies on perioperative pain, ${ }^{12-15}$ a consistent finding was that anxious patients had exaggerated expectations of pain whilst less anxious patients were more accurate in their predictions ${ }^{15}$ experience of pain, however, was not consistently related to anxiety. Arntz et al. ${ }^{15}$ described the need for several disconfirmatory experiences in order for anxious patients to become more accurate in their predictions of pain during treatment. Kent and Warren's study, ${ }^{13}$ however, found no direct associations of change in anxiety with expected/experienced pain discrepancy nor with confidence in the typicality of the appointment.

The lack of effect of coping strategies of pain in Chaves and Brown's study ${ }^{14}$ was suggested to be due to the low pain levels involved in the treatment procedures (mean rating less than 2 on a 10point scale). The study by Hargreaves et al. ${ }^{12}$ was a small psycho-immunological investigation of individual variation in stress-provoked pain modulation.

Feinmann et al. ${ }^{16}$ investigated the psychological factors influencing postoperative pain and analgesic consumption in 103 oral surgery patients attending DH (Table 4). Pain measures included VAS at one and three days postoperatively and analgesic use; while psychological measures included STAI, VAS (anxiety), General Health

Table 4 Studies detailing patients' reactions in dental clinics

\begin{tabular}{|c|c|c|c|c|c|}
\hline Study & Subject groups & $\begin{array}{l}\text { Number } \\
\text { Drop-out }\end{array}$ & Pain measures & Psychological measures & Findings \\
\hline Feinmann et al. & $\begin{array}{l}\text { Adult oral surgery } \\
\text { patients attending DH }\end{array}$ & $\begin{array}{l}103 \\
6 \%\end{array}$ & $\begin{array}{l}\text { VAS and analgesic } \\
\text { use }\end{array}$ & STAI, VAS, GHO, EPO, STAI & $\begin{array}{l}\text { High trait anxiety }(p<0.01) \text {, neuroticism } \\
(p<0.001) \text { predicts persistent pain } \\
\text { post-operatively }\end{array}$ \\
\hline Hansson et al. & $\begin{array}{l}\text { Consecutive adult } \\
\text { patients attending DH } \\
\text { for wisdom } \\
\text { teeth removal }\end{array}$ & $\begin{array}{l}100 \\
0 \%\end{array}$ & $\begin{array}{l}\text { VAS (postoperatively } \\
\text { for } 72 \mathrm{hrs} \text { ) and } \\
\text { analgesic use }\end{array}$ & $\begin{array}{l}\text { VAS; GHO, BHS, } \\
\text { preoperatively; VAS, } \\
\text { immediately postoperatively }\end{array}$ & $\begin{array}{l}\text { Personality characteristics unrelated to } \\
\text { post-operative pain }\end{array}$ \\
\hline Faucett et al. & $\begin{array}{l}\text { Adult patients } \\
\text { attending DH for } \\
\text { wisdom teeth removal }\end{array}$ & $\begin{array}{l}543 \\
0 \%\end{array}$ & VAS (postoperatively) & Ethnic differences only & $\begin{array}{l}\text { Women }(p<0.001) \text { and younger patients } \\
(p<0.01) \text { reported more pain; subjects of } \\
\text { European descent reported less pain than } \\
\text { those of Black American }(P<0.01) \text { and } \\
\text { Latino }(p<0.05) \text { descent }\end{array}$ \\
\hline Gidron et al. & $\begin{array}{l}\text { Adult patients } \\
\text { attending DH for third } \\
\text { molar removal }\end{array}$ & $\begin{array}{l}67 \\
20 \%\end{array}$ & $\begin{array}{l}\text { Likert-like scale (for } 6 \\
\text { days postoperatively) }\end{array}$ & $\begin{array}{l}\text { PANAS, question regarding } \\
\text { expectancy of functional } \\
\text { recovery, IBES, CISS }\end{array}$ & Psychosocial factors did not predict pain \\
\hline
\end{tabular}


Table 5 Studies detailing patients' reactions in dental clinics

\begin{tabular}{|c|c|c|c|c|c|c|}
\hline Study & $\begin{array}{l}\text { Subject } \\
\text { groups }\end{array}$ & $\begin{array}{l}\text { Number } \\
\text { Drop-out }\end{array}$ & Pain measures & $\begin{array}{l}\text { Psychological } \\
\text { measures }\end{array}$ & Manipulation & Findings \\
\hline $\begin{array}{l}\text { Morosko } \\
\text { and } \\
\text { Simmons }\end{array}$ & $\begin{array}{l}\text { Dental students } \\
\text { randomly } \\
\text { selected from } \\
\text { a group of } \\
\text { volunteers }\end{array}$ & $\begin{array}{l}40 \\
0 \%\end{array}$ & $\begin{array}{l}\text { Toothache detection } \\
\text { and tolerance } \\
\text { thresholds in } \\
\text { response to electrical } \\
\text { stimulation }\end{array}$ & SHSS & $\begin{array}{l}\text { Audio-analgesia: } \\
\text { music and 'white } \\
\text { noise' }\end{array}$ & $\begin{array}{l}\text { Pain detection and tolerance thresholds } \\
\text { raised with audio-analgesia }(p<0.05) \text { and } \\
\text { especially with volume of white noise under } \\
\text { the subject's control }(p<0.01) \text {; no effect of } \\
\text { implicit vs. explicit suggestion nor of } \\
\text { susceptibility to suggestion }\end{array}$ \\
\hline Wardle & $\begin{array}{l}\text { Adult patients } \\
\text { attending } \\
\text { general dental } \\
\text { practice }\end{array}$ & $\begin{array}{l}73 \\
0 \%\end{array}$ & Likert-type scale & $\begin{array}{l}\text { Anxiety: } \\
\text { 5-points scales }\end{array}$ & $\begin{array}{l}\text { Sensation } \\
\text { information; } \\
\text { distraction; perceived } \\
\text { control; normal } \\
\text { practice }\end{array}$ & $\begin{array}{l}\text { Lower pain and anxiety ratings in sensation } \\
\text { information group cf. normal }(p<0.05) \text {; } \\
\text { lower pain ratings in perceived control } \\
\text { group ( } p<0.05) \text {; no group differences in } \\
\text { dentist's ratings }\end{array}$ \\
\hline $\begin{array}{l}\text { Katcher } \\
\text { et al. }\end{array}$ & $\begin{array}{l}\text { Adult patients } \\
\text { attending } \mathrm{DH}\end{array}$ & $\begin{array}{l}42 \\
? \%\end{array}$ & $\begin{array}{l}\text { Patient Comfort } \\
\text { Index }\end{array}$ & $\begin{array}{l}\text { DAS, observer } \\
\text { ratings, SHSS, } \\
\text { BP, PR }\end{array}$ & $\begin{array}{l}\text { Aquarium } \\
\text { contemplation; poster } \\
\text { contemplation; poster } \\
\text { contemplation with } \\
\text { hypnosis; aquarium } \\
\text { contemplation with } \\
\text { hypnosis; non- } \\
\text { intervention control }\end{array}$ & $\begin{array}{l}\text { Aquarium contemplation } \pm \text { hypnosis, poster } \\
\text { contemplation with hypnosis produced } \\
\text { greater patient comfort } \\
\text { than poster contemplation and } \\
\text { non-intervention control ( } p<0.001 \\
\text { to } p<0.06 \text { ). Hypnosis did not augment the } \\
\text { relaxing effect of aquarium contemplation }\end{array}$ \\
\hline
\end{tabular}

Questionnaire (GHQ) preoperatively; and Eysenck Personality Questionnaire (EPQ) and STAI postoperatively. Following that it was revealed that high trait anxiety, neuroticism and psychiatric morbidity predict persistent pain postoperatively. A study by Hansson et al. ${ }^{17}$ found that personality characteristics are unrelated to postoperative pain following a study on 100 patients undergoing surgical removal of impacted third molars.

Faucett et $a l .{ }^{18}$ conducted a study to examine differences in severity of postoperative pain among 543 patients from four ethnic groups (Asian, Black American, European and Latino). The results showed that women and younger patients reported more pain, and subjects of European descent reported less pain than those of Black American and
Latino descent. Gidron et al. ${ }^{19}$ examined the physical and psychosocial predictors of adolescents' recovery from oral surgery. Sixty-seven adolescents undergoing surgical removal of third molars participated in the study and the results showed that psychological factors did not predict pain.

Four studies focused on postoperative pain. ${ }^{16-19}$ Of these, three examined the predictive capacity of psychosocial factors on postoperative pain and recovery following surgical removal of third molars. One study found psychological factors, including postoperative anxiety, to predict postoperative pain. ${ }^{16}$ Two further studies failed to show any such prediction. ${ }^{17,19}$ This discrepancy is likely to be due in part to the differing measures taken. Only Feinmann et al. ${ }^{16}$ and Hansson et al. ${ }^{17}$ used a stand- ard validated psychological measure (GHQ) and only the former study specifically measured anxiety.

In Feinmann's study ${ }^{16}$ a regression analysis, in addition to correlation, would have informed regarding the relative predictive powers of the psychological variables. Hansson's study ${ }^{17}$ had the advantage of a standardised surgical procedure but, in recording on an hourly basis, may have incorporated too many measures. Gidron's study ${ }^{19}$ failed to control for analgesic consumption.

Dental pain with psychological manipulation Morosko and Simmons ${ }^{20}$ conducted a study which involved 40 male dental students randomly selected to measure the effect of audio-analgesia on pain threshold and pain tolerance (Table 5).

Table 6 Studies detailing patients' reactions in dental clinics

\begin{tabular}{|c|c|c|c|c|c|c|}
\hline Study & Subject groups & $\begin{array}{l}\text { Number } \\
\text { Drop-out }\end{array}$ & Pain measures & $\begin{array}{l}\text { Psychological } \\
\text { measures }\end{array}$ & Manipulation & Findings \\
\hline Houle et al. & Student volunteers & $\begin{array}{l}28 \\
0 \%\end{array}$ & VAS & TAQ & $\begin{array}{l}\text { Progressive } \\
\text { muscle relaxation } \\
\pm \text { analgesia; hypnotic } \\
\text { induction } \pm \text { analgesia }\end{array}$ & $\begin{array}{l}\text { Both conditions reduced the } \\
\text { reported strength }(p<0.001) \text { and } \\
\text { unpleasantness }(p<0.01) \text { of tooth } \\
\text { pulp stimulation as well as pain } \\
\text { detection threshold }(p<0.01)\end{array}$ \\
\hline Baron et al. & Endodontic patients & $\begin{array}{l}188 \\
5 \%\end{array}$ & VAS & VAS, STAI, IDCI & $\begin{array}{l}\text { Emotional focus and } \\
\text { sensory focus }\end{array}$ & $\begin{array}{l}\text { High pain experienced by group high in } \\
\text { desired 'dental control' but low in felt } \\
\text { 'control', eliminated by sensory focus } \\
\text { manipulation but not emotional focus }\end{array}$ \\
\hline Logan et al. & $\begin{array}{l}\text { Adult fee paying } \\
\text { endodontic patients }\end{array}$ & $\begin{array}{l}330 \\
1 \%\end{array}$ & $\begin{array}{l}\text { DDS (pre- and } \\
\text { postoperatively), } \\
0-4 \text { rating of } \\
\text { experienced pain }\end{array}$ & $\mathrm{IDCl}$ & $\begin{array}{l}\text { Sensory focus; } \\
\text { procedural } \\
\text { information; } \\
\text { combination of both; } \\
\text { no intervention }\end{array}$ & $\begin{array}{l}\text { Sensory focus reduced pain experience } \\
\text { for the high desire/low felt control } \\
\text { subgroup }\end{array}$ \\
\hline
\end{tabular}




\begin{tabular}{|c|c|c|c|c|c|c|}
\hline Study & Subject groups & $\begin{array}{l}\text { Number } \\
\text { Drop-out }\end{array}$ & Pain measures & $\begin{array}{l}\text { Psychological } \\
\text { measures }\end{array}$ & Manipulation & Findings \\
\hline Law et al. & $\begin{array}{l}\text { Adult volunteer fee } \\
\text { paying periodontal } \\
\text { patients }\end{array}$ & $\begin{array}{l}110 \\
5 \%\end{array}$ & VAS & STAI, IDCI, VAS & $\begin{array}{l}\text { Stress inoculation } \\
\text { training; filler video }\end{array}$ & $\begin{array}{l}\text { Expected pain unaffected; high } \\
\text { desire/low felt patients in SIT } \\
\text { condition experiences less pain } \\
\text { than neutral condition }(p<0.05)\end{array}$ \\
\hline $\begin{array}{l}\text { Enqvist and } \\
\text { Fischer }\end{array}$ & $\begin{array}{l}\text { Adult patients on } \mathrm{DH} \\
\text { waiting list for third } \\
\text { molar removal }\end{array}$ & $\begin{array}{l}69 \\
4 \%\end{array}$ & $\begin{array}{l}\text { VAS and analgesic } \\
\text { use }\end{array}$ & VAS & $\begin{array}{l}\text { Hypnotic relaxation } \\
\text { induction audiotape } \\
\text { with suggestion for } \\
\text { healing; no intervention }\end{array}$ & $\begin{array}{l}\text { Preoperative level of anxiety } \\
\text { maintained on day of surgery } \\
\text { after intervention, whereas } \\
\text { anxiety increase in control group } \\
(p=0.002)\end{array}$ \\
\hline $\begin{array}{l}\text { Sullivan } \\
\text { and Neish }\end{array}$ & $\begin{array}{l}\text { Students for dental } \\
\text { hygiene treatment }\end{array}$ & $\begin{array}{l}80 \\
0 \%\end{array}$ & $\begin{array}{l}\text { VAS } \\
\text { (postoperatively) }\end{array}$ & $\begin{array}{l}\text { PCS, DAS, } \\
\text { POMS }\end{array}$ & $\begin{array}{l}\text { Disclosure of expected } \\
\text { distress, thoughts and } \\
\text { feelings; control }\end{array}$ & $\begin{array}{l}\text { Catastrophisers reported more pain } \\
\text { than non }(p<0.001) \text { in control } \\
\text { group only. Disclosure reduced } \\
\text { catastrophisers' pain }(p<0.01)\end{array}$ \\
\hline
\end{tabular}

They found that pain detection and tolerance threshold raised with audioanalgesia and especially with the volume of 'white noise' under the subject's control; there was no effect of implicit vs. explicit suggestion nor of susceptibility to suggestion.

Wardle ${ }^{21}$ investigated the effect of psychological management of anxiety and pain during dental treatment of 73 adult patients attending general dental practice; pain was measured using a Likerttype scale (dentist and patient ratings), while anxiety was measured on a 5point scale (dentist and patient ratings); these measurements were acquired in the postoperative phase. Manipulation was based on four conditions: sensation information (with specific reference to pain), distraction (visually interesting stimulus), perceived control (arm-raising encouraged as pause signal) and normal practice. Wardle concluded that the provision of sensation information was the most effective treatment.

Forty-two adult patients attending a DH for tooth extraction were recruited to compare contemplation and hypnosis for the reduction of anxiety and discomfort perioperatively. ${ }^{22}$ Patient Comfort Index (PCI) for pain measures and DAS, observer ratings, SHSS, BP and pulse rate (psychological measures) were obtained from each patient. Manipulation was based on one of five conditions: aquarium contemplation (1), poster contemplation (2), poster contemplation with hypnosis (3), aquarium contemplation with hypnosis (4) and non-intervention control (5). The first, third and fourth conditions produced greater patient comfort and hypnosis did not augment the relaxing effect of aquarium contemplation.

Houle et al. ${ }^{23}$ evaluated the efficacy of hypnosis- and relaxation-induced suggestions for analgesia for reducing the strength and unpleasantness dimensions of pain evoked by noxious tooth pulp stimulation (Table 6). Subjects made threshold determinations of pain and tolerance and used VAS to rate the strength and the unpleasantness of both noxious stimuli before and after receiving either hypnosis- or relaxation-induced analgesia. There were no significant differences in pain reductions between hypnosisand relaxation-induced interventions. However, the percentage reduction in both strength and unpleasantness varied significantly as a function of the type of pain. In Baron et al.'s study, ${ }^{24} 188$ adult endodontic patients were attending a DH. Giving patients instructions to focus on sensory (vs. emotional) stimuli during a root canal procedure significantly reduced self-reported pain, but only among patients who were classified as having a strong desire for control but did not feel in control in dental situations. Among patients who did not feel in control and did not have a strong desire for control, sensory-focus instructions produced greater pain reports than emotion-focus instructions. Moreover, high desire but low control patients reported higher levels of expected pain before treatment than other patient subgroups.

Logan et al. ${ }^{25}$ conducted a study which involved 330 adult endodontic patients attending a DH. Pain measures included Descriptor Differential Scale (DDS), 0-4 rating of experienced pain at one week; psychological measures included IDCI (Iowa Dental Control Index), and the manipulation condition involved sensory focus (physical sensations), procedural information, sensory focus and procedural information or no intervention. Patients in this study were categorised as to how much control they desired and felt. They concluded that sensory focus reduced pain experience for the high desire/low control subgroup; procedural information did not add to this.

One hundred and ten patients were categorised as to their desire for and feelings of control and were randomly assigned, just prior to dental treatment $^{26}$ (Table 7). VAS has been used to record expected and experienced pain (pain measures); STAI, IDCI and VAS for expected and experienced distress (psychological measures); then the volunteers were subjected to either stress inoculation training (training patients to cope with anxiety and stressful situations by learning more functional patterns of self-talk) or a filler video (neutral). The study showed that stress inoculation training significantly reduced pain and increased control only for patients who initially reported a high desire for control coupled with low perceived control. This finding supports the view that the discrepancy between high desire for control and low perceived control plays a casual role in the elevated distress and pain initially reported by patients with such control perceptions. 


\begin{tabular}{l} 
Table 8 Predisposition to pain \\
\hline $\begin{array}{l}\text { Most common psychological characteristics } \\
\text { which predispose to pain }\end{array}$ \\
\hline Dental anxiety \\
\hline Fear of pain \\
\hline Expectation and anticipation of pain \\
\hline Negative dental experience \\
\hline Attitudes towards the dentist \\
\hline Attitudes towards the provision of dental care \\
\hline
\end{tabular}

Enqvist and Fischer ${ }^{27}$ evaluated the effects of preoperative hypnotic techniques used by 69 patients in line for surgical removal of mandibular third molars. VAS has been used as a pain and psychological measure; manipulation involved either a hypnotic relaxation induction audiotape with suggestion for healing and analgesia or no intervention. The preoperative level of anxiety was maintained on the day of surgery after intervention, whereas anxiety increased in the control group; postoperative consumption of analgesics was significantly reduced in the experimental group compared to the control group.

Sullivan and Neish ${ }^{28}$ examined the effects of emotional disclosure on the pain and emotional distress experienced by 80 'catastrophisers' and 'noncatastrophisers' during dental hygiene treatment. Manipulation was either disclosure of expected distress, thoughts and feelings or control (description of previous day's activity). Catastrophisers reported more pain; disclosure reduced catastrophisers' pain.

The discussed studies were generally well-designed with adequate blinding of experimenters and dental staff, and appropriate control groups. A wide variety of interventions were successful in producing some degree of analgesia, mostly for patients undergoing routine dental treatment. Successful manipulation included audio-analgesia, emotive imagery, coping skills and sensory information, perceived control, distraction, progressive muscle relaxation, hypnosis, behavioural therapy and stress inoculation training.

Essentially the above techniques are designed to reduce anxiety. These effects are achieved by relaxation or distraction or by attention to sensations. The relative merits of distraction and attention are unknown. Wardle ${ }^{21}$ found attention to sensation to be more effective in reducing pain and anxiety than a visually interesting stimulus, but suggested that the latter was perhaps not adequately distracting. Wardle also used a non-validated measure of anxiety.

Individual differences in coping strategies may be influential, as in Sullivan and Neish's study; ${ }^{28}$ disclosure of anticipated distress by writing down thoughts and feelings effectively reduced pain experience during dental hygiene treatment, in catastrophising patients.

Hypnosis would appear to have no additional benefit over simpler relaxation techniques. ${ }^{22,23}$ The Houle study ${ }^{23}$ also lacked a control group. In Morosko and Simmons' study, ${ }^{20}$ the lack of control

Table 9 Psychological intervention techniques

\begin{tabular}{|l|l|}
\hline Distraction strategies & Visually interesting stimulus, music \\
\hline Relaxation techniques & $\begin{array}{l}\text { Guided Imagery, deep breathing, progressive relaxation, biofeedback } \\
\text { (coping with pain and stress) }\end{array}$ \\
\hline Hypnosis & Hypnotic relaxation \\
\hline Sensory information & Procedure and typical sensations to be expected, drill sound \\
\hline Perceived control & Arm-raising encouraged as pause signal \\
\hline Positive dental experience & Benefits of introduction to the management by the dentist \\
\hline Systemic desensitisation & Gradual exposure to things inducing anxiety and stress \\
\hline Cognitive behavioural therapy & Calm mind and body, change negative or harmful thinking patterns \\
\hline Psychotherapy & Patients with sever anxiety and phobias \\
\hline Support groups & Offer coping skills and emotional support \\
\hline Dental phobia clinics & Clinics staffed by therapists who deal with severe anxiety \\
\hline
\end{tabular}

group prevented assessment of any practice effect through repeated procedures. The reported increase in pain threshold is likely to have been a function of anxiety reduction, in response to suggestion of analgesia (implicit or explicit), and of perceived control. The Enqvist and Fischer study ${ }^{27}$ assessed pain solely by means of analgesic consumption, a crude measure and an active coping strategy in itself.

Psychological intervention in acute dental pain was found to be a very successful non-invasive measure to reduce pain induced by psychological factors (Table 8) pre-, peri- and postoperatively by employing various psychological interventions (Table 9 shows the most common interventions).

\section{CONCLUSION}

This review provides conclusive evidence that patients with acute dental pain do benefit from psychological intervention; how significant this benefit is when compared with those not receiving any intervention, remains the subject of debate.

1. Vassend 0. Anxiety, pain and discomfort associated with dental treatment. Behav Res Ther 1993; 31: 659-666.

2. McNeil D W, Berryman M L. Components of dental fear in adults? Behav Res Ther 1989; 27: 233-236.

3. Madland G, Feinmann C, Newman S. Factors associated with anxiety and depression in facial arthromyalgia. Pain 2000; 84: 225-232.

4. Lindsay S J, Humphris G, Barnby G J. Expectations and preferences for routine dentistry in anxious adult patients. Br Dent J 1987; 163: 120-124.

5. Maggirias J, Locker D. Psychological factors and perceptions of pain associated with dental treatment. Comm Dent Oral Epidemiol 2002; 30: 151-159.

6. Sigurdsson A, Maixner W. Effects of experimental and clinical noxious counterirritants on pain perception. Pain 1994; 57: 265-275.

7. Edwards R R, Fillingim R B, Yamauchi S et al. Effects of gender and acute dental pain on thermal pain responses. Clin J Pain 1999; 15: 233-237.

8. Karadottir $H$, Lenoir L, Barbierato $B$ et al. Pain experienced by patients during periodontal maintenance treatment. J Periodonto/ 2002; 73: 536-542.

9. Weisenberg M, Kreindler M L, Schachat $R$ et al. Pain: anxiety and attitudes in black, white and Puerto Rican patients. Psychosom Med 1975; 37: 123-135.

10. Antczak-Bouckoms A, Bouckoms A J. Affective disturbance and denial of problems in dental patients with pain. Int J Psychosom 1985; 32: 9-11.

11. Kunzelmann K H, Dunninger P. Dental fear and pain: effect on patient's perception of the dentist. Comm Dent Oral Epidemiol 1990; 18: 264-266.

12. Hargreaves K M, Dionne R A, Mueller G P. Plasma beta-endorphin-like immunoreactivity, pain and anxiety following administration of placebo in oral surgery patients. J Dent Res 1983; 62: 1170-1173.

13. Kent $G$, Warren P. A study of factors associated with changes in dental anxiety. J Dent Res 1985; 64: 1316-1318.

14. Chaves J F, Brown J M. Spontaneous cognitive strategies for the control of clinical pain and 
stress. J Behav Med 1987; 10: 263-276.

15. Arntz A, van Eck M, Heijmans M. Predictions of dental pain: the fear of any expected evil, is worse than the evil itself. Behav Res Ther 1990; 28: 29-41.

16. Feinmann $C$, Ong $M$, Harvey $W$ et al. Psychological factors influencing post-operative pain and analgesic consumption. Br J Oral Maxillofac Surg 1987; 25: 285-292.

17. Hansson P, Ekblom A, Thomsson M et al. Pain development and consumption of analgesics after oral surgery in relation to personality characteristics. Pain 1989; 37: 271-277.

18. Faucett J, Gordon N, Levine J. Differences in postoperative pain severity among four ethnic groups. J Pain Symptom Manage 1994; 9: 383-389.

19. Gidron Y, McGrath P J, Goodday R. The physical and psychosocial predictors of adolescents' recovery from oral surgery. J Behav Med 1995; 18: 385-399.

20. Morosko TE, Simmons F F. The effect of audioanalgesia on pain threshold and pain tolerance. J Dent Res 1966; 45: 1608-1617.

21. Wardle J. Psychological management of anxiety and pain during dental treatment. J Psychosom Res 1983; 27: 399-402.

22. Katcher $A$, Segal $H$, Beck $A$. Comparison of contemplation and hypnosis for the reduction of anxiety and discomfort during dental surgery. Am J Clin Hypn 1984; 27: 14-21.

23. Houle M, McGrath P A, Moran G et al. The efficacy of hypnosis- and relaxation-induced analgesia on two dimensions of pain for cold pressor and electrical tooth pulp stimulation. Pain 1988; 33: 241-251.

24. Baron R S, Logan H, Hoppe S. Emotional and sensory focus as mediators of dental pain among patients differing in desired and felt dental control. Health Psychol 1993; 12: 381-389.

25. Logan H L, Baron R S, Kohout F. Sensory focus as therapeutic treatments for acute pain. Psychosom Med 1995; 57: 475-484

26. Law A, Logan H, Baron R S. Desire for control, felt control, and stress inoculation training during dental treatment. J Pers Soc Psychol 1994; 67: 926-936.

27. Enqvist B, Fischer K. Preoperative hypnotic techniques reduce consumption of analgesics after surgical removal of third mandibular molars: a brief communication. Int J Clin Exp Hypn 1997; 45: 102-108.

28. Sullivan M J, Neish N R. A psychological intervention for reducing pain during dental hygiene treatment. Probe 1999; 33: 23-25, 28-30. 